\title{
Comparison of methods for the detection of biofilm production in coagulase-negative staphylococci
}

\author{
Adilson Oliveira, Maria de Lourdes RS Cunha*
}

\begin{abstract}
Background: The ability of biofilm formation seems to play an essential role in the virulence of coagulase-negative staphylococci (CNS). The most clearly characterized component of staphylococcal biofilms is the polysaccharide intercellular adhesin (PIA) encoded by the icaADBC operon. Biofilm production was studied in 80 coagulasenegative staphylococci (CNS) strains isolated from clinical specimens of newborns with infection hospitalized at the Neonatal Unit of the University Hospital, Faculty of Medicine of Botucatu, and in 20 isolates obtained from the nares of healthy individuals without signs of infection. The objective was to compare three phenotypic methods with the detection of the icaA, icaD and icaC genes by PCR.

Findings: Among the 100 CNS isolates studied, $82 \%$ tested positive by PCR, $82 \%$ by the tube test, $81 \%$ by the TCP assay, and $73 \%$ by the CRA method. Using PCR as a reference, the tube test showed the best correlation with detection of the ica genes, presenting high sensitivity and specificity.

Conclusions: The tube adherence test can be indicated for the routine detection of biofilm production in CNS because of its easy application and low cost and because it guarantees reliable results with excellent sensitivity and specificity.
\end{abstract}

\section{Background}

Coagulase-negative staphylococci (CNS) are the microorganisms most frequently involved in nosocomial infections among neonates. These infections are generally associated with the use of catheters and other medical devices [1]. The capacity to adhere to polymer surfaces and consequent biofilm production are the main virulence factors of CNS, especially S. epidermidis, the most frequently isolated species.

The biofilm protects CNS against the action of antibiotics administered for the treatment of these infections and also against the patient's immune system. Removal of the foreign body is often necessary for cure [2,3]. In this respect, CNS infections seem to be related to the health condition of the patient and to the production of this extracellular polysaccharide $[4,5]$.

\footnotetext{
* Correspondence: cunhamlr@ibb.unesp.br

UNESP - Univ Estadual Paulista, Department of Microbiology and Immunology, Biosciences Institute Bacteriology Laboratory, Botucatu, SP,
} Brazil

(c) 2010 Cunha et al; licensee BioMed Central Ltd. This is an open access article distributed under the terms of the Creative Commons Attribution License (http://creativecommons.org/licenses/by/2.0), which permits unrestricted use, distribution, and reproduction in any medium, provided the original work is properly cited.
The biofilm consists of layers of cell clusters embedded in a matrix of extracellular polysaccharide, called polysaccharide intercellular adhesin (PIA), which consists of $\beta-1,6-\mathrm{N}$-acetylglycosamine and is synthesized by $\mathrm{N}$-acetylglucosaminyltransferase [6]. PIA is involved in cell-cell adhesion and is essential for biofilm production by CNS, which is observed in most clinical strains of $S$. epidermidis $[7,8]$.

The synthesis of PIA is mediated by the products of the chromosomal ica gene (intercellular adhesion), which are organized in an operon structure. This operon contains the icaADBC genes, in addition to the icaR gene which exerts a regulatory function and is transcribed in the opposite direction. Once this operon is activated, four proteins are transcribed, IcaA, IcaD, IcaB and $\mathrm{IcaC}$, which are necessary for the synthesis of PIA [9-11]. PIA is synthesized from UDP-N-acetylglucosamine by $\mathrm{N}$-acetylglucosaminyltransferase, which is encoded by the ica locus, particularly icaA. The expression of this gene alone induces low enzymatic activity and the production of low amounts of polysaccharide. 
However, the simultaneous expression of icaA and icaD promotes a significant increase in $\mathrm{N}$-acetylglucosaminyltransferase, with a consequent increase in the amount of polysaccharide, forming oligomers of $10-20 \beta-1,6-\mathrm{N}$ acetylglucosamine residues $[12,13]$. The ica $C$ gene, when expressed concomitantly with icaA and icaD, induces the synthesis of longer oligomers that contain up to 130 residues. The $i c a B$ gene probably encodes a secretory protein that does not seem to be involved in the biosynthesis of PIA $[14,15]$.

Recent studies have shown that additional components, such as accumulation-associated protein (Aap), DNA and RNA independently or in cooperation with the ica operon, have also been suggested to be important in CNS biofilms [16-18]. Bap [biofilm-associated protein] has been shown to be involved in the initial attachment, intercellular adhesion and biofilm formation of $S$. aureus [19]. Interestingly, Bap homologue protein (Bhp) is found in human S. epidermidis strains and induces an alternative mechanism of biofilm formation that does not depend on PIA [20].

Various methods are currently used in medical areas for the detection of biofilm production, including visual assessment by electron microscopy using different types of microscopes. The most versatile and effective nondestructive approach for studying biofilms is confocal laser scanning microscopy (CLSM). CLSM markedly reduces the need for pretreatments such as disruption and fixation, which reduce or eliminate the evidence of microbial relationships, complex structures and biofilm organization, without the limitations encountered with scanning electron microscopes [21-23]. Bridier et al. [24] proposed CLSM combined with the use of 96-well microtiter plates compatible with high resolution imaging for the study of biofilm formation and structure. The authors reported that the combined use of microplates and confocal imaging proved to be a good alternative to other high throughput methods commonly used since it permits the direct, in situ qualitative and quantitative characterization of biofilm architecture.

However, qualitative methods, such as the tube adherence test described by Christensen et al. [25] and the Congo red agar (CRA) method described by Freeman et al. [26], and quantitative methods such as the tissue culture plate (TCP) assay described by Christensen et al. [27] are used in routine laboratories. Molecular techniques such as the polymerase chain reaction (PCR), which amplifies the genes involved in biofilm production, complement these methods.

The objective of the present study was to investigate biofilm production in CNS strains isolated from clinical specimens of newborns hospitalized at the Neonatal Unit of the University Hospital, Faculty of Medicine of Botucatu, and in isolates obtained from the nares of healthy individuals by three phenotypic methods and by PCR for detection of the icaA, icaD and icaC genes.

\section{Materials and methods \\ Strains}

A total of $100 \mathrm{CNS}$ isolates were studied, including 80 isolated from clinical specimens obtained from newborns hospitalized at the Neonatal Unit of the University Hospital, Faculty of Medicine, Universidade Estadual Paulista (UNESP), Botucatu Campus, and 20 obtained from the nares of healthy subjects. The following international reference strains were used as controls: the non-biofilm producers S. epidermidis ATCC 12228 and S. warneri ATCC 10209 (negative control), and the biofilm producers S. epidermidis ATCC 35983, S. simulans ATCC 27851 and S. xylosus ATCC 29979 (positive control).

\section{Identification of coagulase-negative staphylococci}

The isolates obtained from the clinical specimens were seeded onto blood agar and stained by the Gram method for the determination of purity, morphology and specific staining. After confirmation of these characteristics, the strains were submitted to catalase and coagulase tests. The genus Staphylococcus was differentiated from Micrococcus according to the method described by Baker et al. [28].

The simplified scheme proposed by Cunha et al. [29] was used for the identification of CNS based on sugar utilization tests. After species confirmation, the isolates were stored in nutrient broth with glycerol in a freezer at $-70^{\circ} \mathrm{C}$.

\section{Study of biofilm production \\ Investigation of biofilm production by adherence to borosilicate test tubes (Christensen et al. 1982)}

Biofilm production was investigated by the tube adherence test proposed by Christensen et al. [25]. A positive result was defined as the presence of a layer of stained material adhered to the inner wall of the tubes. The exclusive observation of a stained ring at the liquid-air interface was not considered to be positive.

Investigation of biofilm production by adherence to polystyrene plates (modified method of Christensen et al. 1985)

The quantitative method of adherence to polystyrene plates (TCP) proposed by Christensen et al. [27] was also used in the present study, with modifications. These modifications included an increase in the glucose concentration of TSB from $0.25 \%$ to $2 \%$, a longer incubation period ( $24 \mathrm{~h}$ instead of $18 \mathrm{~h}$ ), and determination of optical density in dry plates and plates washed with $95 \%$ ethanol using filters of 492 and $540 \mathrm{~nm}$. Analysis of the sensitivity and specificity of the TCP method using 
PCR as a parameter showed that the use of dry plates and of the $540-\mathrm{nm}$ filter provided the best sensitivity (97.6\%) and specificity (94.4\%) when compared to ethanol-containing plates and the 492-nm filter, and was therefore chosen for analysis of the results.

The isolates were classified into three categories: nonadherent, optical density equal to or lower than 0.111 ; weakly adherent, optical density higher than 0.111 or equal to or lower than 0.222 ; strongly adherent, optical density higher than 0.222 .

When the cut-off corresponded to non-adherent the isolates were classified as negative, and as positive when the cut-off corresponded to weakly or strongly adherent. Sensitivity and specificity were calculated for each situation in relation to the concomitant presence of the icaA and icaD or icaADC genes using PCR as the reference method.

\section{Investigation of biofilm production by the Congo red agar} method proposed by Freeman et al. (1989)

Phenotypic characterization of biofilm production was performed by culture of the CNS isolates on CRA plates as proposed by Freeman et al. [26]. According to the authors, biofilm producers form black colonies on CRA, whereas non-producers form red colonies. The Congo red dye directly interacts with certain polysaccharides, forming colored complexes [30].

A five-color reference scale was used to accurately determine all color variations shown by the colonies. Isolates presenting two tones of black, bright black (BB) and dryopaque black $(\mathrm{OB})$, were classified as biofilm producers, whereas red, pink and bordeaux colonies were classified as negative. In some cases, red and bordeaux subcolonies arose in the center of black colonies (BB) after $48 \mathrm{~h}$ of culture. These colonies were removed and subcultured for 24 $\mathrm{h}$ on CRA to obtain pure isolates of the producer and non-producer variants. These isolates were also submitted to the phenotypic tests (tube adherence test and TCP assay) and to detection of the ica genes by PCR.

\section{Detection of the icaA, icaC and icaD genes specific for biofilm production}

The procedure used for detection of the ica genes involved the following steps: nucleic acid extraction using the Illustra kit (GE Healthcare), PCR amplification according to the parameters described by Arciola et al. [31], and visualization of the amplified products by gel electrophoresis.

\section{Statistical analysis}

Sensitivity and specificity [32] were evaluated by comparing the phenotypic methods used for the detection of biofilm production and PCR for the detection of the genes involved in biofilm synthesis. All isolates carrying at least two of the genes studied were considered to be positive for biofilm production. Sensitivity and specificity were evaluated as follows: sensitivity - proportion of
PCR-positive isolates (concomitant presence of the icaA and icaD or icaADC genes) that tested positive by the other phenotypic methods; specificity - proportion of PCR-negative isolates (no detection of the ica gene) that tested negative by the phenotypic methods.

Agreement between the tests and the presence of the ica genes was evaluated using the kappa index $[33,34]$.

\section{Results}

Isolates

A total of $100 \mathrm{CNS}$ isolates were studied, including 80 isolated from clinical specimens obtained from newborns hospitalized at the Neonatal Unit of the University Hospital, Faculty of Medicine, Universidade Estadual Paulista (UNESP), Botucatu, Brazil, and 20 obtained from the nares of healthy subjects. Among the 80 isolates obtained from clinical specimens, 50 were isolated from catheter tips and 30 by blood culture.

\section{Identification of coagulase-negative staphylococci}

S. epidermidis was the most frequently detected species (81\%), followed by S. cohnii (4\%), S. saprophyticus (4\%), S. warneri (4\%), S. haemolyticus (2\%), S. xylosus (2\%), S. capitis (2\%), and S. lugdunensis (1\%).

Table 1 shows the frequency of CNS species according to clinical specimen. S. epidermidis was the CNS species most frequently isolated from clinical specimens (catheter and blood culture) and from nares specimens of healthy subjects. S. haemolyticus, S. xylosus, S. lugdunensis and S. capitis were also isolated from clinical specimens, whereas $S$. cohnii and S. saprophyticus were only isolated from the nares of healthy subjects. S. warneri was isolated from blood culture and nares specimens.

\section{Study of biofilm production \\ Detection of the icaA, icaC and icaD genes specific for biofilm production}

The presence of the icaA (103 bp), icaC (400 bp) and icaD (198 bp) genes in the CNS isolates was

Table 1 Frequency of coagulase-negative staphylococci isolated from different clinical specimens

\begin{tabular}{lccccc}
\hline Species & $\begin{array}{c}\text { Catheter } \\
\text { tip }\end{array}$ & $\begin{array}{c}\text { Blood } \\
\text { culture }\end{array}$ & $\begin{array}{c}\text { Nasal } \\
\text { fossa }\end{array}$ & $\begin{array}{c}\text { Overall } \\
\text { frequency }\end{array}$ & $\begin{array}{c}\text { Percentage } \\
\text { (\%) }\end{array}$ \\
\hline S. epidermidis & 45 & 27 & 9 & 81 & 81 \\
S. cohnii & 0 & 0 & 4 & 4 & 4 \\
S. haemolyticus & 1 & 1 & 0 & 2 & 2 \\
S. saprophyticus & 0 & 0 & 4 & 4 & 4 \\
S. warneri & 0 & 1 & 3 & 4 & 4 \\
S. xylosus & 2 & 0 & 0 & 2 & 2 \\
S. lugdunensis & 0 & 1 & 0 & 1 & 1 \\
S. capitis & 2 & 0 & 0 & 2 & 2 \\
\hline Total & 50 & 30 & 20 & 100 & 100 \\
\hline
\end{tabular}


demonstrated by the amplification of the corresponding fragments (Figure 1). The icaA and icaD genes were detected concomitantly in 40 (40\%) of the 100 CNS isolates, and the $i c a A, i c a C$ and $i c a D$ genes were detected concomitantly in 42 (42\%). None of the genes studied could be identified in 18 (18\%) isolates. Except for $S$. haemolyticus and S. capitis, all other CNS species were positive for the genes studied.

\section{Study of biofilm production by the tube adherence test (Christensen et al. 1982)}

Investigation of biofilm production by the tube adherence test showed that 82 of the 100 isolates were biofilm producers, including 44 strains isolated from catheter tips, 23 isolated by blood culture, and 15 isolated from nares specimens. With respect to species, 70 (85.4\%) $S$. epidermidis isolates were positive. Biofilm production was also observed in $S$. warneri $(\mathrm{n}=4), S$. cohnii $(\mathrm{n}=$ 3), S. xylosus $(\mathrm{n}=2)$, S. saprophyticus $(\mathrm{n}=2)$, and $S$. lugdunensis $(\mathrm{n}=1)$.

The sensitivity and specificity of the tube adherence test were calculated using the presence of the ica genes as a parameter. The results showed $100 \%$ sensitivity and $100 \%$ specificity of the tube test [24] when compared to

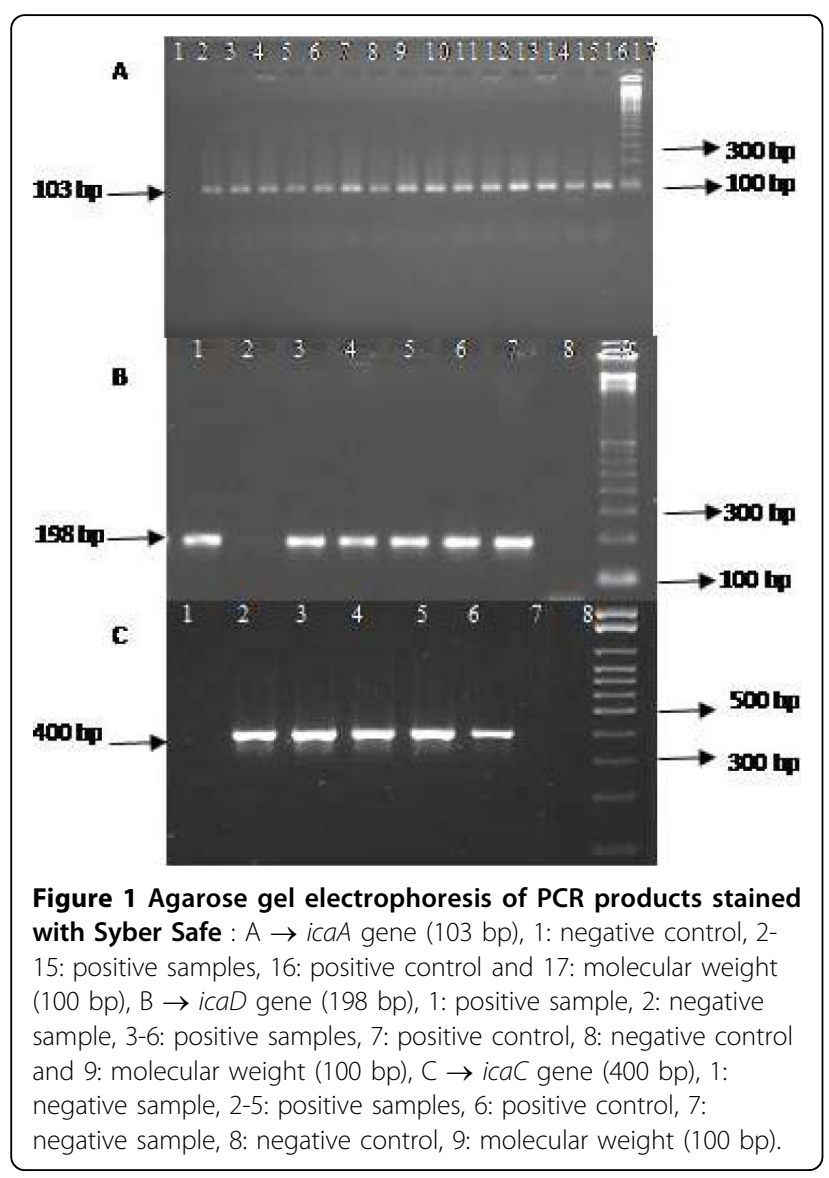

PCR (concomitant presence of the icaA and icaD or icaACD genes).

\section{Study of biofilm production by the tissue culture plate method (Christensen et al. 1985)}

Among the 100 isolates studied, 35 (35\%) were classified as weakly adherent and $46(46 \%)$ as strongly adherent, for a total of 81 (81\%) positive isolates and 19 (19\%) negative isolates. Forty-four (54.3\%) of the 81 positive isolates were obtained from catheter tips, 21 (25.9\%) from blood culture, and 16 (19.8\%) from nares specimens. Among the 19 negative isolates, 6 (31.6\%) were obtained from catheter tips, 9 (47.4\%) from blood culture, and 4 (21.0\%) from nares specimens.

The TCP assay using a 540-nm filter presented 97.6\% sensitivity and $94.4 \%$ specificity when compared to PCR recognizing the concomitant presence of the $i c a A$ and $i c a D$ or $i c a A C D$ genes. One nares specimen tested false-positive, i.e., it was classified as strongly adherent but did not carry any of the ica genes. Two blood culture samples tested false-negative, i.e., they were classified as non-adherent but tested positive for the icaACD genes.

Analysis of agreement showed moderate agreement (kappa $=0.44$ ) between the TCP assay and the concomitant presence of the icaA and icaD or icaACD genes.

To determine the relationship between the amount of biofilm and the concomitant presence of the icaACD genes, the positive results classified as strongly adherent obtained by spectrophotometric analysis of dry plates using a 540-nm filter were compared to those obtained by PCR. The results showed that 26 (56.5\%) of the 46 strongly adherent isolates carried the icaACD genes. Moderate agreement (kappa $=0.44$ ) was observed between strongly adherent isolates and the concomitant presence of the icaACD genes.

\section{Study of biofilm production by the Congo red agar method proposed by Arciola et al. (2001)}

The international reference strains S. simulans ATCC 27851 and S. xylosus ATCC 29979, used as positive control, exhibited a bright black color, whereas S. epidermidis ATCC 12228 and S. warneri ATCC 10209 (negative controls) formed bordeaux and bordeaux metallic colonies, respectively.

Among the 100 CNS isolates studied, 73 formed black colonies on CRA, including bright black colonies in 41 and dry black colonies in 32 . The results revealed 27 non-biofilm producers whose colony color ranged from pink $(2 \%)$ to red (7\%) and bordeaux (18\%). Two variants were observed among black colonies (BB), one with a bordeaux spot in the center and the other with a red spot. The center of these colonies was removed and subcultured for $24 \mathrm{~h}$ on CRA to obtain pure isolates. 
After isolation, the two subcolonies were found to be negative, presenting a red and bordeaux color, respectively. After reisolation from the center, these isolates also tested negative by the tube test and TCP assay and the icaADC genes were not detected by PCR.

Nine isolates formed bordeaux colonies and were therefore considered to be negative. However, these isolates tested positive for the concomitant presence of the $i c a A$ and $i c a D$ genes or icaACD genes and were classified as false-negative when compared to PCR. Two of these isolates were obtained by blood culture and seven were isolated from nares specimens.

The CRA method presented $89 \%$ sensitivity and $100 \%$ specificity when compared to PCR recognizing the concomitant presence of the icaA and icaD or icaACD genes.

\section{Comparison of biofilm detection methods in CNS}

Table 2 shows the comparison between the phenotypic methods for the detection of biofilm production and the presence of the $i c a A$ and $i c a D$ genes or icaACD genes. The tube adherence test was the phenotypic method showing the best sensitivity (100\%) and specificity (100\%) in biofilm detection when compared to PCR.

\section{Discussion}

In view of the large number of infections caused by biofilm-producing bacterial, a reliable method for their diagnosis is necessary. In the present study, $100 \mathrm{CNS}$ strains isolated from clinical specimens of newborns and from the nares of healthy subjects were analyzed. The results revealed $S$. epidermidis as the most frequently isolated species in both clinical and nares specimens, corresponding to $81 \%$ of all strains isolated. Other CNS species were also identified, including S. cohnii, S. saprophyticus, S. warneri, S. haemolyticus, S. xylosus, $S$. capitis, and S. lugdunensis. Similar results have been reported in other studies $[35,36]$. The finding of S. epidermidis as the most frequently isolated species in most studies might be due to the fact that this microorganism possesses certain mechanisms that favor its adaptation to some sites, with this species being the most prevalent bacterium in human skin and mucosa [37].

The present results showed no difference in the frequency of biofilm production between isolates obtained from clinical samples and from nares specimens of healthy subjects, irrespective of the detection method used. Similar biofilm production by CNS strains isolated from different sources, including clinical specimens, environment and microbiota of healthy individuals, has also been reported by other investigators [35,38].

The icaA and icaD genes were detected concomitantly in $40 \%$ of the $100 \mathrm{CNS}$ isolates studied and the icaACD genes in $42 \%$. These results differ from those reported by Cafiso et al. [9] who also investigated the presence of genes involved in biofilm production. In that study, 35\% of the isolates were positive for the $i c a A$ and $i c a D$ genes and only 4 isolates carried the icaACD genes. Some isolates only carried the icaD gene. In the present study, PCR was found to be an efficient method for detection of the ica operon. Other investigators also reported PCR to be an important tool for the identification of ica genes since the technique is simple, rapid and reliable and only requires minimal amounts of DNA [9,39]. PCR was used in this study as a reference for the phenotypic method based on several studies [9,39-41] that demonstrated the efficiency of this technique in detecting the genes of the ica operon. In addition, these genes are important virulence markers of clinical CNS isolates since their expression is associated with the production of PIA, the most clearly characterized component of staphylococcal biofilms.

With respect to the phenotypic methods, the tube adherence test presented $100 \%$ sensitivity and $100 \%$ specificity when compared to PCR recognizing the concomitant presence of the icaA and icaD or icaACD genes. Ruzicka et al. [40] also reported good sensitivity and specificity for the tube test and PCR when analyzing isolates obtained from infections. According to Morales et al. [10] and Cunha et al. [42], the test provides

Table 2 Sensitivity and specificity of phenotypic methods for the detection of biofilm production in coagulasenegative staphylococci

\begin{tabular}{|c|c|c|c|c|c|}
\hline Method & & ica Positive ${ }^{*}$ & ica negative ${ }^{* *}$ & Sensitivity \% & Specificity \% \\
\hline \multirow[t]{2}{*}{ Tube test } & Adherent & 82 & 0 & 100 & 100 \\
\hline & Non-adherent & 0 & 18 & & \\
\hline \multirow[t]{2}{*}{ Plate test } & Adherent & 80 & 1 & 97,6 & 94,4 \\
\hline & Non-adherent & 2 & 17 & & \\
\hline \multirow[t]{2}{*}{ CRA test } & Adherent & 73 & 0 & 89 & 100 \\
\hline & Non-adherent & 9 & 18 & & \\
\hline
\end{tabular}

\footnotetext{
* ica positive: Positive for icaA and icaD or icaACD.

** ica negative: Negative for icaA and icaD or icaACD.

CRA: Congo red agar.
} 
reliable results for biofilm detection in CNS and is adequate for routine use.

According to the present study and reports in the literature [43], the expression of the ica genes is highly variable and can be induced by variations in the culture conditions, such as an increase in the concentration of sugars or other substances that induce stress. Mathur et al. [44] also obtained better results when the glucose concentration of TSB was increased to $1 \%$ and the period of incubation was prolonged to $24 \mathrm{~h}$. The addition of large amounts of sugar to a medium colonized with CNS induces a stress condition which, in turn, stimulates fermentation, thus increasing the production of PIA and consequent biofilm production [5].

In the present study, $81 \%$ of the isolates were positive in the TCP test, with the observation of moderate agreement (0.44) between this test and PCR recognizing the concomitant presence of the icaA and icaD or icaACD genes. Similar results have been reported by Arciola et al. [45] who used the TCP assay for the detection of biofilm-producing isolates, with $81.2 \%$ of the strains testing positive.

According to Gerke et al. [14], when the icaC gene is expressed concomitantly with the icaA and icaD genes, oligomers of up to $130 \mathrm{UDP}-\mathrm{N}$-acetylglucosamine residues are synthesized and the production of PIA thus increases. To confirm the results reported by these authors and to determine the reliability of the TCP method in terms of the quantification of biofilm production, the relationship between strongly adherent isolates and the concomitant presence of the three ica genes (icaA, icaC and icaD) detected by PCR was evaluated. The results showed that $56.5 \%$ of strongly adherent isolates carried the three genes. Moderate agreement (0.44) was observed between strongly adherent isolates and the concomitant presence of the icaACD genes.

In the present study, the colonies grown on CRA presented diverse colors, thus, a five-color scale was adopted for comparison of the results of the CRA test and PCR in order to correlate the variation in colony color with the presence of the ica genes. Colonies presenting a bright black and dry black color were classified as positive and those presenting a red, pink or bordeaux color as negative. Color scales were also adopted in other studies using the CRA test for better diagnostic performance, but color tones different from those proposed in this study were used. Very black, black and almost black colonies were classified as positive and bordeaux, red and very red colonies as negative $[31,46]$. In the present study, two black color variants were observed, one with a bordeaux dot in the center and the other with a red dot. These colonies were removed and subcultured for 24 in CRA to obtain pure isolates. All isolated subcolonies were again plated onto
CRA plates and were found to be negative, showing a bordeaux and red color, respectively, and no icaADC genes were detected by PCR, similar to the findings of Arciola et al. [46].

In the present study, $73 \%$ of the 100 isolates tested by the CRA method were positive. Similar results have been reported in the study of Cafiso et al. [9], in which $83 \%$ of CNS strains isolated from catheter-associated infections were positive in the CRA test. However, lower positivity rates in this test have been reported in other studies. In investigations on the detection of slime production by $S$. epidermidis strains isolated from catheter [46] and prosthesis-associated [31] infections, 49\% and $57 \%$ positive isolates were identified by the CRA method, respectively. Using the CRA method, Silva et al. [36] observed biofilm production in only $25 \%$ of CNS strains isolated from clinical specimens of newborns in a neonatal intensive care unit.

Comparison between the CRA test and the results obtained by PCR revealed nine CNS isolates forming bordeaux colonies which tested positive for the concomitant presence of the icaA and icaD genes or icaACD genes, with these results thus being false-negative when compared to PCR. Arciola et al. [31] identified eight isolates whose colony color ranged from red to bordeaux and that were classified as negative; however, the ica genes were detected in all of them. Cafiso et al. [9] observed three CNS isolates that were negative for biofilm production in the CRA test but contained the complete ica operon. In another study, six isolates that carried the icaA and icaD genes detected by PCR were negative in the CRA test [46]. Although PCR detects the presence of genes irrespective of their expression, PCRpositive isolates should be considered to be potential biofilm producers.

The CRA test is easier and faster to perform than other phenotypic tests. However, it is slightly imprecise in the identification of positive isolates when compared to molecular analysis of the genes involved in biofilm production, a fact also observed by Fitzpatrick et al. [47].

The present results demonstrated the presence of intercellular adhesion genes (icaACD) and consequent biofilm production in most CNS isolates. The proportion of biofilm-positive/ica-positive versus biofilm-positive/ica-negative strains was $82: 0 \%, 80: 1 \%$ and $73: 0 \%$ by the tube test, TCP assay and CRA, respectively. In the study of Jiang et al. [17], the proportion of biofilm-positive/ica-positive versus biofilm-positive/ica-negative strains was $22: 2 \%$. In another study investigating S. epidermidis clinical strains isolated from blood cultures, this proportion was $85: 2 \%$ [48]. Qin et al. [49] studied the two biofilm-positive/ica-negative strains SE1 and SE4 identified among 101 clinical isolates of $S$. 
epidermidis collected at Ruijin Hospital, Shanghai, China [17]. The authors investigated the aap and bhp genes that induce an alternative PIA-independent mechanism of biofilm formation. However, the two genes were not detected in the SE1 and SE4 strains, but were present in the RP62A reference strain (biofilm-positive/ica-positive). These authors suggested a novel molecular mechanism mediating biofilm formation in SE1 and SE4 clinical isolates. This mechanism needs to be further investigated.

In the present study, the tube adherence test showed the best correlation with the PCR results and can be indicated for the routine detection of biofilm production in CNS.

\section{Conclusion}

The present results demonstrated the presence of intercellular adhesion genes (icaACD) and consequent biofilm production in most CNS isolates. The presence of this biofilm, in turn, facilitates the development of infections by compromising the immune system of the patient and contributing to the failure of antibiotic therapy, which may result in recurrent infections and the emergence of multiresistant pathogens. In addition, the results suggest the use of the tube adherence test for the routine detection of biofilm production in CNS because of its easy application and low cost and because it guarantees reliable results with excellent sensitivity and specificity.

\section{Acknowledgements \\ The support from FAPESP, CNPq and FUNDUNESP is gratefully acknowledged.}

\section{Authors' contributions}

$\mathrm{AO}$ : Responsible for conceiving the idea of the study, performed the microbiological tests, and wrote the article. MLRSC: Responsible for conceiving the idea, coordinating laboratory work, data analysis, and manuscript writing. All authors read and approved the final manuscript.

\section{Competing interests}

The authors declare that they have no competing interests.

Received: 18 May 2010 Accepted: 14 October 2010 Published: 14 October 2010

\section{References}

1. Stoll BJ, Hansen N, Fanaroff AA, Wright LL: Late-onset sepsis in very low birth weight neonates: the experience of the NICHD Neonatal Research Network. Pediatric 2002, 110:285-291.

2. Costa FS, Miceli MH, Anaissie EJ: Mucosa or skin as source of coagulasenegative staphylococcal bacteremia. Clin Infect Dis 2004, 4:278-286.

3. Klingenberg C, Aarag E, Ronnestad A, Sollid JE, Abrahamsen MD, Kjeldsen G, Flaegstad T: Coagulase-negative staphylococcal sepsis in neonates - association between antibiotic resistance, biofilm formation and the host inflammatory response. Ped Infec Dis 2005, 24:817-822.

4. Goldmann DA, Pier GB: Pathogenesis of infections related to intravascular catheterization. Clin Microbiol 1993, 6:176-192.

5. Vuong C, Otto M: Staphylococcus epidermidis infections. Microb Infect 2002, 4:481-489.
6. Mack D, Riedewald J, Rohde H, Magnus T, Feucht HH, Elsner HÁ, Laufs R, Rupp ME: Essential functional role of the polysaccharide intercellular adhesin of Staphylococcus epidermidis in hemagglutination. Infect and Immun 1999, 67:1004-1008.

7. Mack D, Sabottke A, Dobinsky S, Rohde H, Horstkotte MA, Knobloch JKM: Differential expression of methicillin resistance by different biofilmnegative Staphylococcus epidermidis transposon mutant classes. Antimicrob Agents Chemother 2002, 46:178-183.

8. Vuong C, Voyich JM, Fischer ER, Braughton KR, Whitney AR, DeLeo FR, Otto M: Polysaccharide intercellular adhesin (PIA) protects Staphylococcus epidermidis against major components of the human innate immune system. Cell Microbiol 2004, 6:269-275.

9. Cafiso V, Bertuccio T, Santagati M, Campanile F, Amicosante G, Perilli MG, Selan L, Artini M, Nicoletti G, Stefani S: Presence of the ica operon in clinical isolates of Staphylococcus epidermidis and its role in biofilm production. Clin Microbiol Infect 2004, 10:1081-1088.

10. Morales M, Mendez-Alvarez S, Martin-Lopes JV, Marreiro C, Freytes CO: Biofilm: the microbial "bunker" for intravascular catheter-related infection. Support Care Cancer 2004, 12:701-707.

11. Nilsdotter-Augustiinsson A, Claesson C, Lindgren PE, LundqvistGustafsson H, Ohman L: Adherence of Staphylococcus epidermidis to extracellular matrix proteins and effects of fibrinogen-bound bacteria on oxidase activity and apoptosis in neutrophils. APMIS 2005, 113:361-373.

12. Dobinski S, Bartscht K, Mack D: Influence of Tn917 insertion of transcription of the icaADBC operon in six biofilm-negative transposon mutants of Staphylococcus epidermidis. Plasmid 2002, 47:10-17.

13. Gotz F: Staphylococcus and biofilms. Mol Microbiol 2002, 43:1367-1378.

14. Gerke C, Kraft A, Sussmuth R, Schweitzer O, Gotz F, Kraft A, Sussmuth R, Schweitzer O, Gotz F: Characterization of the Nacetylglucosaminyltransferase activity involved in the biosynthesis of the Staphylococcus epidermidis polysaccharide intercellular adhesion. J Biol Chem 1998, 273:18586-18593.

15. Von Eiff C, Peters G, Heilmann C: Pathogenesis of infections due to coagulase-negative staphylococci. Lancet Infect Dis 2002, 2:677-685.

16. Chokr A, Watier D, Eleaume H, Pangon B, Ghnassia JC, Mack D, Jabbouri S: Correlation between biofilm formation and production of polysaccharide intercellular adhesion in clinical isolates of coagulase-negative staphylococci. Int J Med Microbiol 2006, 296:381-388.

17. Jiang J, Sun JY, Ou YZ, Qin ZQ, Chen JM, Qu D: Influence of ica transcription on biofilm phenotype of Staphylococcus epidermidis clinical isolates. Shanghai Med J 2006, 29:40-44.

18. Fredheim EGA, Klingenberg C, Rohde H, Frankenberger S, Gaustad P, Flægstad T, Sollid JE: Biofilm formation by Staphylococcus haemolyticus. J Clin Microbiol 2009, 47:1172-1180.

19. Cucarella C, Solano C, Valle J, Amorena B, Lasa I, Penades JR: Bap, a Staphylococcus aureus surface protein involved in biofilm formation. $J$ Bacteriol 2001, 183:2888-2896.

20. Tormo MA, Knecht E, Gotz F, Lasa I, Penades JR: Bap-dependent biofilm formation by pathogenic species of Staphylococcus: evidence of horizontal gene transfer? Microbiology 2005, 151:2465-2475.

21. Lawrence JR, Neu TR: Confocal laser scanning microscopy for analysis of microbial biofilms. Meth Enzymol 1999, 310:131-144.

22. Costerton W, Veeh R, Shirtliff M, Pasmore M, Post C, Ehrlich G: The application of biofilm science to the study and control of chronic bacterial infections. J Clin Invest 2003, 112:1466-1477.

23. Tolker-Nielsen T, Brinch UC, Ragas PC, Andersen JB, Molin S: Development and dynamics of Pseudomonas sp. biofilms. J Bacteriol 2000, 182:6482-6489.

24. Bridier A, Dubois-Brissonnet F, Boubetra A, Thomas V, Briandet R: The biofilm architecture of sixty opportunistic pathogens deciphered using a high throughput CLSM method. J Microbiol Methods 2010, 82:64-70.

25. Christensen GD, Bisno AL, Simpsom WA, Beachey EH: Adherence of slime producing strains of Staphylococcus epidermidis to smooth surfaces. Infect Immun 1982, 37:318-326.

26. Freeman DJ, Falkner FR, Keane CT: New method for detecting slime production by coagulase-negative staphylococci. J Clin Pathol 1989, 42:872-874.

27. Christensen GD, Simpson WA, Yonger JJ, Baddor LM, Barrett FF, Melton DM, Beachey EH: Adherence of coagulase-negative staphylococci to plastic tissue culture plates: a quantitative model for the adherence of staphylococci to medical devices. J Clin Microbiol 1985, 22:996-1006. 
28. Baker JS: Comparison of various methods for differentiation of staphylococci and micrococci. J Clin Microbiol 1984, 19:875-879.

29. Cunha MLRS, Sinzato YK, Silveira LVA: Comparison of methods for the identification of coagulase-negative staphylococci. Mem Inst Oswaldo Cruz 2004, 99:855-860.

30. Jain A, Agarwal A: Biofilm production, a marker of pathogenic potential of colonizing and commensal staphylococci. J Microbiol Methods 2009, 76:88-92.

31. Arciola CR, Gamberini S, Campoccia D, Visai L, Speziale P, Baldassari L Montanaro $L$ : A multiplex PCR method for the detection of all five individual genes of ica locus in Staphylococcus epidermidis. A survey on 400 clinical isolates from prosthesis-associated infections. J Biomed Mater Res A 2005, 75:408-413.

32. Sox HC: Probability theory in the use of diagnostic tests. An introduction to critical study of literature. Ann Inter Med 1986, 104:60-66.

33. Fleiss JL: Statistical methods for rates and proportions. New York: John Wiley, 21981.

34. Siegel S, Castellan NN: Nonparametric Statistics for the Behavioral Sciences. New York: McGraw-Hill, 21988.

35. Alcaraz LE, Satorres SE, Lucero RM, Centrorbi ONP: Species identification, slime production and oxacillin susceptibility in coagulase-negative staphylococci isolate from nosocomial specimens. Braz J Microbiol 2003, 34:45-51.

36. Silva GDI, Kantzanou M, Justice A, Massey RC, Wilkinson AR, Day NPJ, Peacock SJ: The ica operon and biofilm production in coagulase-negative staphylococci associate with carriage and disease in a neonatal intensive care unit. J Clin Microbiol 2002, 40:382-388.

37. Gemmell CG: Virulence characteristics of Staphylococcus epidermidis. J Med Microbiol 1986, 22:287-289.

38. Vogel L, Sloos JH, Spaargaren J, Suiker I, Dijkshoorn L: Biofilm production by Staphylococcus epidermidis isolates associated with catheter related bacteremia. Diagn Microbiol Infect Dis 2000, 36:139-141.

39. Arciola $C R$, Baldassarri L, Montanaro L: Presence of icaA and icaD genes and slime production in a collection of staphylococcal strains from catheter-associated infection. J Clin Microbiol 2001, 39:2151-2156.

40. Ruzicka F, Holá V, Votava M, Tejkalová M, Horvát R, Heroldová M, Woznicová V: Biofilm detection and the clinical significance of Staphylococcus epidermidis isolates. Folia Microbiol 2004, 49:596-600.

41. Gad GFM, El-Feky MA, El-Rehewy MS, Hassan MA, Abolella H, El-Baky RMA: Detection of icaA, icaD genes and biofilm production by Staphylococcus aureus and Staphylococcus epidermidis isolated from urinary tract catheterized patients. J Infect Dev Ctries 2009, 3:342-351.

42. Cunha MLRS, Rugolo LMSS, Lopes CAM: Study of virulence factors in coagulase-negative staphylococci isolated from newborns. Mem Inst Oswaldo Cruz 2006, 101:661-668.

43. Cho SH, Naber K, Hacker J, Ziebuhr W: Detection of the icaADBC gene cluster and biofilm formation in Staphylococcus epidermidis isolates from catheter-related. Int J Antimicrob Agents 2002, 19:570-575.

44. Mathur T, Singhal S, Klan S, Upadhyay DJ, Fatma T, Rattan A: Detection of biofilm formation among the clinical isolates of Staphylococci: An evaluation of three different screening method. Indian J Med Microbiol 2006, 24:25-29.

45. Arciola CR, Campoccia D, Baldassari L, Donati ME, Pirini V, Gamberini Simonetta G, Montanaro L: Detection of biofilm formation in Staphylococcus epidermidis from implant infections. Comparison of a PCR-method that recognizes the presence of ica genes with two classic phenotypic methods. J Biomed Mater Res A 2006, 76:425-430.

46. Arciola CR, Campoccia D, Gamberini S, Cervel-Lati M, Dontati E, Montanaro L: Detection of slime production by means of an optimized Congo red agar plate based on a colourimetric scale in Staphylococcus epidermidis clinical isolates genotyped for ica locus. Biomaterials 2002, 23:4233-4239.

47. Fitzpatrick F, Humphreys $\mathrm{H}, \mathrm{O}^{\prime} \mathrm{Gara}$ P: Evidence for icaADBC-independent biofilm development mechanism in methicillin-resistant Staphylococcus aureus clinical isolates. J Clin Microbiol 2005, 43:1973-1976.

48. Ziebuhr W, Heilmann C, Gotz F, Meyer P, Wilms K, Straube E, Hacker J: Detection of the intercellular adhesion gene cluster (ica) and phase variation in Staphylococcus epidermidis blood culture strains and mucosal isolates. Infect Immun 1997, 65:890-896.
49. Qin Z, Yang X, Yang L, Jiang J, Ou Y, Molin S, Qu D: Formation and properties of in vitro biofilms of ica-negative Staphylococcus epidermidis clinical isolates. J Med Microbiol 2007, 56:83-93.

doi:10.1186/1756-0500-3-260

Cite this article as: Oliveira and Cunha: Comparison of methods for the detection of biofilm production in coagulase-negative staphylococci. BMC Research Notes 2010 3:260.

\section{Submit your next manuscript to BioMed Central and take full advantage of:}

- Convenient online submission

- Thorough peer review

- No space constraints or color figure charges

- Immediate publication on acceptance

- Inclusion in PubMed, CAS, Scopus and Google Scholar

- Research which is freely available for redistribution

Submit your manuscript at www.biomedcentral.com/submit
C Biomed Central 